\title{
KAJIAN IMPLEMENTASI CAMBUK DI ACEH SETELAH PERATURAN GUBERNUR NOMOR 5 TAHUN 2018
}

\section{STUDY IMPLEMENTATION CAMBUK IN ACEH AFTER ACEH GOVERNOR REGULATIONS NUMBER 5 IN 2018}

\author{
Marzuki M. Ali ${ }^{1}$, Indriansyah ${ }^{2}$, Dewi Ariani ${ }^{3}$ \\ ${ }^{1,2,3}$ Satpol PP dan WH Aceh, Jl. Tengku Haji Muhammad Daud Beureuh, No. 19, \\ Gampong Laksana, Bandar Baru, Kec. Kuta Alam, \\ Kota Banda Aceh, Aceh, Indonesia. \\ E-mail: marzuki.kiki461@gmail.com
}

Diterima: 03/03/2020; Disetujui: 31/03/2020

\begin{abstract}
ABSTRAK
Qanun Aceh Nomor 7 Tahun 2013 tentang Hukum Jinayat Pasal 247 ayat (1) Pelaksanaan 'Uqubat adalah kewenangan dan tanggung jawab Jaksa Penuntut Umum. Ayat (3) Dalam melaksanakan tugas Jaksa Penuntut Umum dapat meminta bantuan kepada instansi/lembaga terkait. Pasal 252 ayat (1) Pelaksanaan 'Uqubat cambuk dilakukan oleh jaksa dengan menyiapkan tempat pencambukan, menentukan waktu dan menunjuk pencambuk. Salah satu asas dalam Qanun Acara Jinayat dan Pergub Pelaksanaan Hukum Acara Jinayat adalah Tadabbur (Pembelajaran). Dalam penegakan Syariat Islam di Aceh salah satu tujuan hukum itu adalah untuk penyadaran bagi terpidana, agar tidak lagi mengulangi perbuatan yang sama (residivis), sehingga cukup satu kali dalam hidupnya melakukan pelanggaran Syariat Islam. Namun kenyataan bahwa semenjak Pergub tersebut diundangkan hanya 2 (dua) kali dilaksanakan eksekusi cambuk di Lapas, dan selanjutnya tidak pernah dilakukan lagi eksekusi cambuk di Lapas, hal tersebut karena adanya kendala teknis, efektivitas dan juga banyak penolakan dari masyarakat Aceh.
\end{abstract}

Kata Kunci: Implementasi Cambuk, Peraturan Gubernur Nomor 5 Tahun 2018 


\begin{abstract}
Aceh Regional Regulation Number 7 of 2013 concerning Jinayat Law Article 247 paragraph (1) Implementation of Uqubat is the authority and responsibility of the Public Prosecutor. Paragraph (3) In carrying out the duties of the Public Prosecutor may request assistance from the relevant agencies / institutions. Article 252 paragraph (1) Implementation of the whip Uqubat is carried out by the prosecutor by preparing the caning place, determining the time and designating the whip. One of the principles in the Aceh Regional Regulation of the Jinayat and the Governor of the Jinayat Procedure Law is Tadabbur (Learning). In upholding Islamic Sharia in Aceh, one of the objectives of the law is to raise awareness of the convicted person, so that they no longer repeat the same act (recidivist), so that it is enough once in their life to violate Islamic Law. However, the fact that since the Aceh Regional Regulation was enacted only 2 times the execution of flogging in Prison, and subsequently no more caning in Prison was carried out, this was due to technical obstacles, effectiveness and many rejections from the people of Aceh.
\end{abstract}

Keywords: caning implementation, Aceh Governor Regulations Number 5 In 2018

\title{
PENDAHULUAN
}

Qanun Aceh Nomor 7 Tahun 2013 tentang Hukum Acara Jinayat Pasal 2, Penyelenggaraan hukum acara Jinayat dilaksanakan berdasarkan asas a. legalitas; b. keadilan dan keseimbangan; c. perlindungan hak asasi manusia; d. praduga tidak bersalah (presumption of innocence); e. ganti kerugian dan rehabilitasi; f. peradilan menyeluruh, sederhana, cepat, dan biaya ringan; g. peradilan terbuka untuk umum; h. kekuasaan hakim yang sah, mandiri dan tetap; i. bantuan hukum bagi Terdakwa; dan j. pembelajaran kepada masyarakat (tadabbur), dalam penjelasan pasal 2 huruf j menyebutkan bahwa Yang dimaksud dengan "Pembelajaran kepada masyarakat (tadabbur)" adalah semua proses peradilan mulai dari penangkapan sampai kepada pelaksanaan 'uqubat harus mengandung unsur pendidikan agar masyarakat mematuhi hukum, mengetahui proses penegakan hukum dan perlindungan masyarakat, adanya perlindungan hak asasi manusia yang seimbang terutama bagi korban dan pelaku jarimah. Pembelajaran dimaksud disini tidak hanya pada proses eksekusi cambuk akan tetapi pada saat penangkapan, penyidikan, penuntutan dan persidangan serta pada saat proses eksekusi cambuk harus menjadi pelajaran masyarakat, sehingga masyarakat diharapkan tidak melakukan tindak pidana jinayat tersebut. Selanjutnya pasal 1 angka 37 Qanun Aceh Nomor 7 Tahun 2013 tentang Hukum Acara Jinayat menyebutkan bahwa 'Uqubat adalah hukuman yang dijatuhkan oleh hakim terhadap pelanggaran Jarimah. Kemudian pemberlakuan qanun juga sesuai dengan Pasal 5, Qanun Aceh 
ini berlaku untuk lembaga penegak hukum dan setiap orang yang berada di Aceh.

Dalam menjalankan asas tadabbur bagi masyarakat terutama pada pelaksanaan putusan hakim sebagaimana diatur dalam Qanun Aceh Nomor 7 Tahun 2013 tentang Hukum Jinayat Pasal 247 ayat (1) Pelaksanaan 'Uqubat adalah kewenangan dan tanggung jawab Jaksa Penuntut Umum. Ayat (3) Dalam melaksanakan tugas Jaksa Penuntut Umum dapat meminta bantuan kepada instansi/lembaga terkait. Pasal 252 ayat (1) Pelaksanaan 'Uqubat cambuk dilakukan oleh jaksa dengan menyiapkan tempat pencambukan, menentukan waktu dan menunjuk pencambuk. Ayat (2) Untuk penentuan tempat dan waktu pencambukan sebagaimana dimaksud pada ayat (1) Jaksa berkoordinasi dengan Ketua Mahkamah Syar'iyah, Kepala Dinas Kesehatan dan Instansi yang membawahi Wilayatul Hisbah Kabupaten/kota setempat. Pasal 253 ayat (1) Atas permintaan jaksa, instansi yang membawahi Wilayatul Hisbah kabupaten/kota setempat mempersiapkan pencambuk. Ayat (2) Kepala Instansi yang membawahi Wilayatul Hisbah sebagaimana dimaksud pada ayat (1) memberitahukan kesiapan petugas pencambuk kepada jaksa sebelum waktu pencambukan. Pasal 275, Atas permintaan Jaksa, pengawalan terhukum dan pengamanan pelaksanaan 'Uqubat cambuk dilakukan oleh Kepolisian Resort atau Wilayatul Hisbah Kabupaten/kota setempat.
Pelaksanaan putusan hakim oleh Jaksa yang dibantu oleh Wilayatul Hisbah sebagaimana amanah Qanun Aceh Nomor 7 Tahun 2013 tentang Hukum Acara Jinayat dilaksanakan didepan umum, sebagaimana dimaksud pada Pasal 262 ayat (1) 'Uqubat cambuk dilaksanakan di suatu tempat terbuka dan dapat dilihat oleh orang yang hadir. Dalam pelaksanaan eksekusi cambuk mulai dari tahun 2005 sudah dilaksanakan di depan umum yang pertama dilaksanakan di Kabupaten Bireuen di masjid Kabupaten Bireuen, dan sampai dengan tahun 2017 pelaksanaan eksekusi cambuk masih dilaksanakan di depan umum.

Peraturan Gubernur Aceh Nomor 5 Tahun 2018 tentang Pelaksanaan Hukum Acara Jinayat Pasal 30 ayat (1) Uqubat cambuk dilaksanakan di suatu tempat terbuka dan dapat dilihat oleh orang yang hadir, ayat (2) Pelaksanaan Uqubat cambuk sebagaimana dimaksud pada ayat (1) tidak boleh dihadiri oleh anak-anak dibawah usia 18 (delapan belas) tahun. (3) Tempat terbuka sebagaimana dimaksud pada ayat (1) bertempat di Lembaga Permasyarakatan/ Rutan/ Cabang Rutan, ayat (4) Pelaksanaan uqubat cambuk di Lembaga Pemasyarakatan atau Rutan/Cabang Rutan sebagaimana dimaksud pada ayat (3) dilaksanakan setelah adanya naskah kerjasama antara Pemerintah Aceh dengan Kanwil Kementerian Hukum dan HAM RI.

Atas dasar Peraturan Gubernur Aceh Nomor 5 Tahun 2018 tersebut di atas para 
aparat penegak hukum seperti Jaksa, Hakim, Wilayatul Hisbah dan Kementerian Hukum dan HAM sebagai pihak yang melaksanakan putusan pengadilan merasa bingung karena aturan yang diatur dalam Qanun Aceh Nomor 7 Tahun 2013 tentang Hukum Acara Jinayat sangat jelas dan tidak perlu diatur lagi dalam Peraturan Gubernur, kemudian apabila dilihat dari Aspek kesiapan Lembaga Pemasyarakatan, tidak mungkin dilaksanakan di Lapas, sehingga sampai saat ini tidak bisa dilakukan eksekusi di Lapas. Berdasarkan uraian di atas maka yang menjadi rumusan masalah dalam penelitian ini yaitu bagaimana proses pelaksanaan eksekusi cambuk setelah lahirnya Peraturan Gubernur Aceh Nomor 5 Tahun 2018. Dari latar belakang masalah di atas menulis mencoba meneliti tentang Implementasi Cambuk setelah Lahirnya Peraturan Gubernur Nomor 5 Tahun 2018.

\section{METODE PENELITIAN}

Penelitian ini menggunakan pendekatan hukum empiris (yuridis-empiris) yaitu hukum sebagai gejala masyarakat, sebagai institusi sosial atau perilaku yang mempola dengan teknik analisis uraian dalam bentuk verbal atau deskriptif. Jenis penelitian yang digunakan adalah studi kasus.

Dalam studi kasus, unit analisis merupakan salah satu komponen desain yang sangat penting. Unit analisis pada penelitian ini adalah pihak-pihak yang terlibat dalam pelaksanaan eksekusi cambuk di Aceh, dalam hal ini Petugas Wilayatul Hisbah.

Adapun Sumber dan Teknik Pengumpulan Data yaitu data dalam penelitian ini bersumber dari data primer dan data sekunder. Data primer diperoleh langsung dari sumber pertama atau data yang diperoleh langsung dari informan dan pengamatan langsung di lokasi penelitian. Pengumpulan data primer pada penelitian ini menggunakan teknik sebagai berikut, yaitu Wawancara, Observasi.

Adapun data sekunder adalah data yang diperoleh dari dokumen-dokumen resmi, bukubuku, hasil penelitian yang berwujud laporan dan sebagainya. Data sekunder dalam penelitian ini dikumpulkan dengan menggunakan penelitian kepustakaan, yaitu data sekunder yang dibutuhkan diperoleh dengan cara mengumpulkan dan menelaah berbagai informasi dan data yang bersumber dari bahanbahan hukum. Analisis data dalam penelitian ini dilakukan secara deskriptif kualitatif. Data-data yang telah didapat dari hasil wawancara dan observasi terlebih dahulu direduksi dan dikategorisasi. Data yang telah direduksi dan dikategorisasi kemudian disintesis sehingga membentuk sekumpulan informasi yang dapat disajikan dalam bentuk susunan pernyataan naratif. 
HASIL PENELITIAN DAN PEMBAHASAN

\section{A. Upaya Penolakan Implementasi Pergub}

\section{Aceh Nomor 5 Tahun 2018}

Peraturan Gubernur Nomor 5 Tahun 2018 tentang Pelaksanaan Hukum Acara Jinayat merupakan peraturan pelaksanaan yang diperintahkan oleh Qanun Aceh Nomor 7 Tahun 2013 tentang Hukum Acara Jinayat dan Qanun Aceh Nomor 6 Tahun 2014 tentang Hukum Jinayat, sebagaimana disebutkan dalam ketentuan Pasal 23 ayat (5), Pasal 36 ayat (4), Pasal 50 ayat (4), Pasal 74 ayat (2), Pasal 87 ayat (4), Pasal 100, Pasal 249 ayat (6), Pasal 250 ayat (4), Pasal 284 ayat (2) Qanun Aceh Nomor 7 Tahun 2013 tentang Hukum Acara Jinayat, yang memerintahkan Gubernur untuk membuat peraturan Pelaksana, begitu juga dengan ketentuan Pasal 4 ayat (7), Pasal 67 ayat (2) dan Pasal 68 ayat (4) Qanun Aceh Nomor 6 Tahun 2014 tentang Hukum Jinayat.

Namun dalam Pasal 262 ayat (1) 'Uqubat cambuk dilaksanakan di suatu tempat terbuka dan dapat dilihat oleh orang yang hadir, ayat (2) Pelaksanaan 'Uqubat cambuk sebagaimana dimaksud pada ayat (1) tidak boleh dihadiri oleh anak-anak dibawah umur 18 (delapan belas) tahun, dalam penjelasan pasal 262 disebutkan sangat jelas, artinya tidak perlu ada penafsiran atau peraturan lanjutan untuk dijadikan sandaran, karena sudah cukup jelas menyatakan bahwa cambuk dilakukan di tempat terbuka dan dapat dilihat oleh orang yang hadir.
Namun karena desakan politik dari beberapa pihak, seperti NGO HAM, lembagalembaga internasional, dan Lembaga Swadaya Masyarakat Nasional, agar cambuk dilaksanakan di tempat tertutup, maka Gubernur Aceh mengeluarkan Peraturan Gubernur Aceh Nomor 5 Tahun 2018, terutama pasal 30 yang menyatakan Cambuk di Lembaga Pemasyarakat.

Dengan keluarnya Peraturan Gubernur 5 Tahun 2018 terutama pasal 30 tersebut, mendapatkan reaksi keras dari masyarakat Aceh, Legislatif terutama DPRA, LSM Aceh, yang sangat menolak terbitnya pasal 30 tersebut. Sehingga DPRA dan beberapa LSM melakukan legal standing terhadap pasal 30 Peraturan Gubernur Aceh Nomor 5 Tahun 2018.

Dalam berita Online BBC Senin, 23 April 2018 07:50 WIB diberitakan bahwa Penolakan Pemindahan Hukuman Cambuk Ke Lapas Aceh. Penolakan terhadap pemindahan pelaksanaan hukuman cambuk dari ruang publik ke Lembaga Pemasyarakatan (LP) terus bergulir. Kalangan ormas sipil hingga DPRA di Provinsi Nangroe Aceh Daarussalam (NAD) tetap mendesak aturan baru ini dibatalkan. Ancaman itu antara lain disampaikan oleh Front Pembela Islam (FPI) cabang Aceh. Pada Jum'at (20/4/2018) kemarin ratusan massa FPI dan mahasiswa menggeruduk Kantor Gubernur Aceh menuntut aturan baru itu dibatalkan. Ketua Front Pembela Islam (FPI) cabang Aceh, Muslim at-Tahiry mengatakan pelaksanaan hukuman cambuk di 
dalam Lapas menyalahi ketentuan Qanun dan tidak sesuai dengan kaidah Islam.

Menurut kajian hukum Islam, cambuk harus dilakukan di depan umum, disaksikan orang-orang mukmin. Itu supaya menjadi pelajaran bagi pelaku maupun orang yang menontonnya. Jadi mereka memang harus dibuat malu, biar jera." Katanya. "Kalau dibuat di dalam lapas yang menyaksikan itu kan dari kalangan pelaku kriminal, gimana pelaku akan jera? di lapas itu kan ada pemerkosa, pelaku sodomi yang mungkin kasusnya lebih parah dari yang dilakukan orang yang dicambuk."

Pemindahan pelaksanaan hukuman cambuk ini merupakan bagian dari revisi pelaksanaan hukum pidana Islam bernama Qanun Jinayat yang dituangkan dalam Peraturan Gubernur Aceh Nomor 5 Tahun 2018. Aturan ini merevisi teknis pencambukan pelanggar Perda Syariat Islam. Lokasi pelaksanaan hukuman itu ditetapkan harus digelar di Lembaga Pemasyarakatan (Lapas) dan Rumah Tahanan Negara (Rutan) dan tidak dihadiri anak-anak. Ketua Komisi 1 DPRA, Azhari Cage Ketua Komisi 1 DPRA, Azhari Cage menilai pemindahan lokasi hukuman cambuk ke Lapas batasi akses warga dan menghalangi tujuan hukuman cambuk untuk menciptakan efek jera.

Tidak hanya kalangan masyarakat sipil, Dewan Perwakilan Rakyat Aceh (DPRA) juga menolak aturan baru itu. DPRA telah resmi mengadukan aturan baru ini ke Mahkamah
Agung. Seperti disampaikan Ketua Komisi 1 DPRA, Azhari Cage. "Sidang paripurna khusus DPRA sudah resmi memutuskan DPRA akan menempuh jalur hukum dengan menggugat Pergub Nomor 5 Tahun 2018 ini ke Mahkamah Agung dan kami akan meminta aturan itu dicabut." Katanya. Lebih lanjut Azhari Cage mengatakan, DPRA menilai pemindahan pelaksanaan hukuman cambuk ke Lapas akan membatasi akses masyarakat yang menjadi bagian penting dari tujuan Qanun Jinayat untuk menciptakan efek jera. "Kalau dipindah ke lapas, akses warga untuk menyaksikan pasti terbatas dan warga Aceh sangat alergi dengan lapas." "Padahal dalam Qanun Jinayat sudah diatur rinci, hukuman cambuk harus dilakukan didepan umum, dipanggung dan harus berjarak 12 meter dari warga." tegasnya. Ia juga menambahkan DPRA juga mempersoalkan alasan pemerintah Provinsi Aceh yang mengkaitkan antara hukuman cambuk dengan investasi. "Sejak Qanun Jinayat berlaku, tidak ada masyarakat atau investor yang protes. Kita sepakat investasi di NAD memang harus ditingkatkan tapi itu terkait dukungan pemerintah dan masyarakat, ketersediaan listrik. Tidak ada kaitannya dengan hukuman cambuk." Media Acehonline memberitakan bahwa Ketua Dewan Perwakilan Rakyat Aceh (DPRA) Tgk. Muharuddin mengatakan pihaknya tetap melanjutkan gugatan terhadap Peraturan Gubernur Aceh tentang Anggaran Pendapatan 
dan Belanja Aceh (APBA) 2018 dan Peraturan Gubernur Aceh Nomor 5 Tahun 2018 tentang Tata Pelaksanaan Acara Hukum Jinayat, yang mengatur pelaksanaan hukuman cambuk di lembaga pemasyarakatan (lapas), dengan melakukan judicial review (uji materil) ke Mahkamah Agung (MA).

Gugatan tersebut telah didaftarkan DPRA ke Mahkamah Agung sebelum Gubernr Aceh Irwandi Yusuf ditahan Komisi Pemberantasan Korupsi (KPK) atas kasus dugaan suap dana otonomi khusus Aceh. "Gugatannya sampai saat ini tetap dilanjutkan, karena gugatan ini bukan untuk menghambat realisasi APBA, tetapi untuk memperjelas kepastian hukumnya," kata Tgk. Muharuddin kepada acehonline.info, Jumat (20/7/2018), di ruang kerjanya.

Kepastian hukum tersebut, Tgk. Muhar menjelaskan untuk mengetahui dasar hukum yang membenarkan penyerahan Rancangan APBA dilakukan sebelum adanya kesepatan bersama Kebijakan Umum Anggaran Plafon Prioritas Anggaran Sementara (KUA-PPAS). "Saat pembahasan sebelumnya, DPRA mengembalikan dokumen R-APBA kepada Tim Anggaran Pemerintah Aceh (TAPA), tetapi eksekutif menganggap itu telah diserahkan, mekipun DPRA telah menolak. Sejak diserahkan dokumen R-APBA itu juga telah dihitung waktu 60 hari untuk penetapan pergub. Ini yang akan kita uji, agar adanya kejelasan hukum, untuk menjadi pelajaran ke depan agar tidak terulang ke depan".
Dagobert Runes dalam Uyoh Sadulloh, (2015: 36-37) mengemukakan beberapa persoalan yang berkaitan dengan nilai yang mencakup: a) hakikat nilai, b) tipe nilai, c) kriteria nilai, dan d) status metafisika nilai. Dan Surajiyo, (2009: 147) mengemukakan bahwa moral berasal dari kata Latin mos jamaknya mores yang berarti adat atau cara hidup. Etika dan moral sama artinya, tetapi dalam penilaian sehari-hari ada sedikit perbedaan. Moral dan atau moralitas dipakai untuk perbuatan yang sedang dinilai. Adapun etika dipakai untuk pengkajian sistem nilai yang ada. Eksekusi cambuk yang diberlakukan di Provinsi Aceh sangat erat kaitannya dengan nilai, moral. Hal ini sesuai dengan pendapat Ketua Komisi VII Dewan Perwakilan Rakyat Aceh (DPRA) Gufran Zainal Abidin, MA, bahwa salah satu asas pelaksanaan syariat Islam di Aceh dalam rangka memberikan efek jera atau malu sehingga menjadi pembelajaran/tadabbur bagi yang menyaksikan/masyarakat atau pembelajaran juga bagi terpidana itu sendiri, sehingga diharapkan tidak lagi mengulangi perbuatannya.

Menurut Kepala Bidang Peribadatan Dinas Syariat Islam Kota Banda Aceh yang juga mantan Kepala Bidang Pengawasan Syariat Islam pada Satpol PP dan WH Kota Banda Aceh, menyatakan bahwa semenjak penerapan Syariat Islam di Aceh dan pembentukan Wilayatul Hisbah dari tahun 
2003 sampai dengan sekarang belum ada persoalan yang mendasar atau belum ada kendali yang berarti terkait eksekusi cambuk di halaman terbuka maupun di depan masjid. Dan bahkan masyarakat berharap apabila ada kejadian khalwat atau ikhtilat di kampong mereka, masyarakat berharap agar dapat di cambuk di masjid/meunasah tempat kejadian tersebut karena hal tersebut dapat menjadi pembelajaran atau tadabbur bagi warga tempat kejadian, maupun bagi terpidana sehingga menjadi efek jera atau efek malu bagi mereka yang melakukan pelanggaran syariat Islam, sehingga dengan adanya satu yang dicambuk maka tidak akan terulang lagi kejadian yang sama.

\section{B. Kajian Tadabbur Dalam Eksekusi}

Cambuk Di Aceh Menurut Aparat

\section{Penegak Hukum}

Aparat penegak Hukum seperti Jaksa, Polisi, Wilayatul Hisbah, Hakim merupakan unsur yang bersentuhan langsung dengan penegakan Syariat Islam di Aceh terutama pelaksanaan eksekusi cambuk. Dalam implementasi eksekusi cambuk di lapangan sesuai Qanun Aceh Nomor 7 Tahun 2013 tentang Hukum Acara Jinayat Pasal 247 ayat (1) Pelaksanaan 'Uqubat adalah kewenangan dan tanggung jawab Jaksa Penuntut Umum. Ayat (3) Dalam melaksanakan tugas Jaksa Penuntut Umum dapat meminta bantuan kepada instansi/lembaga terkait. Pasal 253 ayat (1) Atas permintaan jaksa, instansi yang membawahi Wilayatul

Hisbah kabupaten/kota setempat mempersiapkan pencambuk. Ayat (2) Kepala Instansi yang membawahi Wilayatul Hisbah sebagaimana dimaksud pada ayat (1) memberitahukan kesiapan petugas pencambuk kepada jaksa sebelum waktu pencambukan.

Sebagai petugas yang terlibat langsung proses eksekusi cambuk dapat menilai bahwa eksekusi yang dilaksanakan sekarang sangat efektif dan sangat tepat sebagai pembelajaran bagi terpidana dan masyarakat yang menyaksikannya, hal tersebut sebagaimana disampaikan oleh Mursyid, SH Jaksa pada Kejaksaan Negeri Banda Aceh, eksekusi cambuk tidak sama dengan penghukuman seperti pidana biasa yaitu dengan menggunakan asas penghukuman atau pembalasan kepada terpidana, sedangkan pada pidana Jinayat lebih kepada asas tadabbur atau pembelajaran kepada terpidana sendiri dan juga kepada masyarakat yang menyaksikan eksekusi cambuk.

Hal tersebut sesuai dengan teori nilai yang dikemukakan oleh Jujun S. Suriasumantri, (2005: 105) aksiologi adalah teori nilai yang berkaitan dengan kegunaan dari pengetahuan yang diperoleh, dan Syafaruddin, (2008: 33) menyampaikan memberi definisi aksiologi adalah 
menceritakan apa tujuan pengetahuan itu disusun serta hikmah pengetahuan tersebut untuk kemaslahatan manusia.

Menurut pendapat Kepala Kasatpol PP dan WH Kota Banda Aceh Bapak Hidayat, cambuk yang dilakukan di depan umum di wilayah umum atau di halaman masjid Kota Banda Aceh sangat memberikan efek jera atau tadabbur bagi terpidana sendiri maupun bagi masyarakat umum lainnya, hal tersebut dapat dilihat dari laporan bahwa tahun 2018 pelanggaran terhadap qanun syariat Islam menurun drastis, yang sebelumnya hampir setiap minggu ada kasus yang di proses oleh Penyidik PPNS Satpol PP dan WH Kota Banda Aceh, untuk tahun 2018 ini hanya 1 kasus dalam bulan Oktober ini. Artinya masyarakat di Kota Banda Aceh sudah sangat sadar dan patuh terhadap Qanun Syariat Islam.

Kepala Satuan Polisi Pamong Praja dan Wilayatul Hisbah Kabupaten Aceh Besar mengatakan bahwa pada tahun 2018 sesuai laporan bidang Penegakan Peraturan Perundang-Undangan dan Syariat Islam, bahwa eksekusi cambuk pada tahun 2018 lebih sedikit dibandingkan pada tahun 2017, pada tahun 2018 sebanyak 68 kasus yang di eksekusi cambuk, sedangkan pada tahun 2018 hanya 12 kasus yang dilakukan eksekusi cambuk, artinya bahwa dengan adanya eksekusi cambuk yang dipersaksikan, maka masyarakat sudah mulai sadar dan sudah mengambil pembelajaran terhadap orang lain yang dicambuk di depan umum, dan merasa malu apabila di cambuk di depan umum.

\section{Pembelajaran/Tadabbur}

Menurut

\section{Mantan Terpidana Qanun Syariat Islam}

Pemberlakuan syariat Islam di Provinsi Aceh merupakan konsekwensi yuridis yang harus dipatuhi oleh seluruh komponen masyarakat dan ditegakkan oleh aparat penegak hukum di Aceh. Bagi masyarakat yang menjalani hukuman beranggapan merasakan kurang adil terhadap mereka, namun sesuai asas hukum yaitu semua sama dimata hukum "equality before the law" harus benar-benar ditegakkan oleh para penegak hukum di Aceh. Namun di dalam penegakan Syariat Islam di Aceh salah satu tujuan hukum itu adalah untuk penyadaran bagi terpidana, agar tidak lagi mengulangi perbuatan yang sama (residivis), sehingga cukup satu kali dalam hidupnya melakukan pelanggaran Syariat Islam.

Menurut Jamaluddin (Alm) M. Isa, lakilaki kelahiran Kulam Baro, 03 Maret 1973 pekerjaan Tukang Batu, sebagai salah seorang yang pernah menjalani hukuman cambuk di Aceh Besar, merasakan hukuman cambuk yang telah dijatuhkan kepada saya sangat adil dan saya menerima dengan ikhlas di dalam hidup saya cukup menjadi pelajaran hidup yang tidak akan saya lupakan sampai mati, dengan cambuk ini saya merasa malu oleh karena itu saya tidak 
akan mengulangi lagi perbuatan yang sama yaitu melakukan khalwat/Ikhtilat dan saya benar-benar sadar dengan kejadian ini.

Safwani binti Ibrahim perempuan lahir di Lueng Sa, tanggal 31 Desember 1971 pekerjaan Tani alamat Gampong Lampeuneurut Kecamatan Darul Imarah Kabupaten Aceh Besar sebagai salah seorang yang pernah menjalani hukum pelanggaran Qanun Syariat Islam di Kabupaten Aceh Besar merasa tidak pernah dendam dengan siapapun karena dihukum cambuk, saya merasa perbuatan yang saya lakukan merupakan konsekuensi yang harus saya tanggung sendiri, dan tidak pernah menyalahkan orang lain dalam hal ini, saya sangat ikhlas menjalaninya, dan menjadikan pelajaran yang sangat berharga dalam sejarah hidup saya, dan saya akan terus mengingatnya bahkan sampai mati, dan ini merupakan pelajaran yang sangat berharga salama hidup saya.

Pernyataan kedua mantan terpidana tersebut sesuai dengan pendapat Bungkaes menyatakan bahwa "efektifitas adalah hubungan antara output dan tujuan”. Dalam artian efektifitas merupakan ukuran seberapa jauh tingkat output, kebijakan dan prosedur dari organisasi mencapai tujuan yang ditetapkan.
Dalam pengertian teoritis atau praktis, tidak ada persetujuan yang universal mengenai apa yang dimaksud dengan "Efektifitas". Bagaimanapun definisi efektifitas berkaitan dengan pendekatan umum. Bila ditelusuri efektifitas berasal dari kata dasar efektif yang artinya : (1). Ada efeknya (pengaruhnya, akibatnya, kesannya) seperti: manjur; mujarab; mempan; (2). Penggunaan metode/cara, sarana/alat dalam melaksanakan aktivitas sehingga berhasil guna (mencapai hasil yang optimal).

\section{SIMPULAN}

Setelah dikeluarkan Peraturan Gubernur Aceh Nomor 5 Tahun 2018 tentang Pelaksanaan Hukum Acara jinayat khususnya pasal 30 terkait pelaksanaan hukuman cambuk di Lapas, namun banyak masyarakat yang menolak Pergub tersebut sehingga sudah ada upaya hukum dengan menggugat ke Mahkamah Agung RI. Cambuk yang dilaksanakan di Lapas tidak memenuhi Asas Qanun syariat Islam yaitu tadabbur (pembelajaran) bagi pelanggar itu sendiri juga pembelajaran bagi masyarakat umum, karena apabila dicambuk di Lapas, maka masyarakat untuk tidak bisa menyaksikan cambuk tersebut.

\section{DAFTAR PUSTAKA}

\section{A. Buku-Buku}

Ahmad Syahrizal, Peradilan Konstitusi .Cet I, Pradnya Paramit, Jakarta, 2006. 
Akhyar Yusuf Lubis, Filsafat Ilmu: Klasik Hingga Kontemporer, PT Raja Grafindo Persada, jakarta, 2014.

Bernard Arief Sidartha, Ilmu Hukum Indonesia, Genta, Yogyakarta, 2013.

Aditama, Bandung, 2006.Budiono Kusumohamidiojo, Filsafat Hukum (Problematika Ketertiban Yang Adil), Grasindo, Jakarta, 2004.

Harjono, Konstitusi Sebagai Rumah Bangsa Pemikiran Hukum, Sekretariat Jenderal dan Kepaniteraan Mahkamah Konstitusi, Jakarta, 2008.

Muhamad Erwin, Filsafat Hukum: Refleksi Kritis Terhadap Hukum, PT Raja Grafindo Persada, Jakarta, 2013.

Sudikno Mertokusumo, Hukum Acara Perdata Indonesia cet. ke-3, Liberty, Yogyakarta, 1981.

\section{B. Jurnal}

Fri Dolin Siahaan, Jurnal Kompasiana.com, Kajian Filsafat Hukum Terhadap Legal Standing, 11 Januari 2016.

\section{Peraturan Perundang-Undangan}

Undang-Undang Nomor 11 Tahun 2006 tentang Pemerintahan Aceh

Qanun Aceh Nomor 7 Tahun 2013 tentang Hukum Acara Jinayat

Qanun Aceh Nomor 6 Tahun 2014 tentang Hukum Jinayat

Peraturan Gubernur Aceh Nomor 5 Tahun 2018 tentang Pelaksanaan Hukum Acara Jinayat 